\title{
A smart review on the gas transportation model of coalbed methane gas based on the optimized pipeline network
}

Akash TALAPATRA, Abed INAN CHOWDHURY, Md. Shourov UJJAMAN

DOI: 10.30464/jmee.2019.3.2.169

Cite this article as:

Talapatra A., Inan Chowdhury A., Ujjaman M. S. A smart review on the gas transportation model of coalbed methane gas based on the optimized pipeline network. Journal of Mechanical and Energy Engineering, Vol. 3(43), No. 2, 2019, pp. 169-176.

\section{VOLUME 3(43) | No. 2 | JUNE 2019}

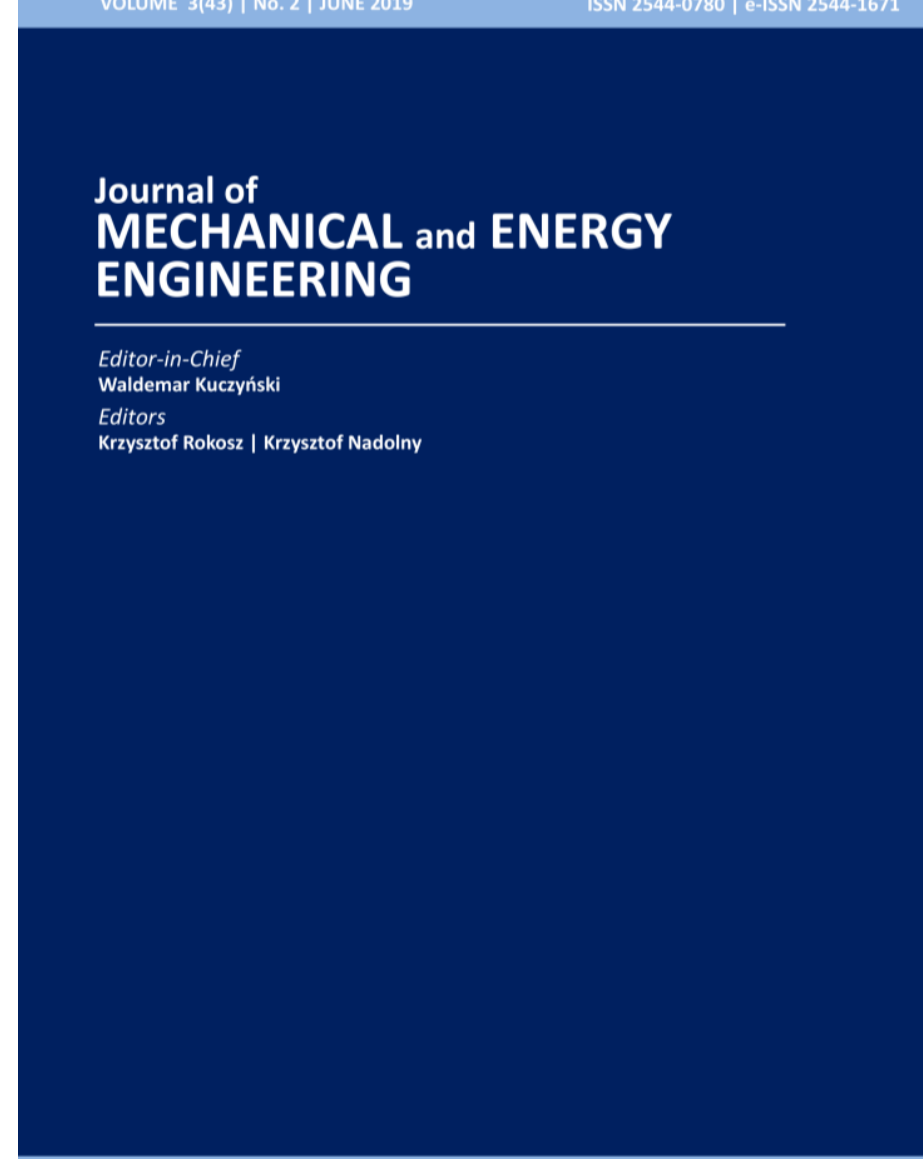

Publishing House of the Koszalin University of Technology | Koszalin 2019
Journal of Mechanical and Energy

Engineering

Website: jmee.tu.koszalin.pl

ISSN (Print): 2544-0780

ISSN (Online): 2544-1671

Volume: 3(43)

Number: 2

Year: 2019

Pages: 169-176

Article Info:

Received 20 May 2019

Accepted 9 June 2019

\section{Open Access}

This article is distributed under the terms of the Creative Commons Attribution 4.0 (CC BY 4.0) International License (http://creativecommons.org/licenses/by/4.0/), which permits unrestricted use, distribution, and reproduction in any medium, provided you give appropriate credit to the original author(s) and the source, provide a link to the Creative Commons license, and indicate if changes were made. 


\title{
A SMART REVIEW ON THE GAS TRANSPORTATION MODEL OF COALBED METHANE GAS BASED ON THE OPTIMIZED PIPELINE NETWORK
}

\author{
Akash TALAPATRA $^{1 *}$, Abed INAN CHOWDHURY ${ }^{1}$, Md. Shourov UJJAMAN $^{1}$ \\ ${ }^{1 *}$ Chittagong University of Engineering and Technology, Faculty of Mechanical Engineering, \\ Department of Petroleum and Mining Engineering, Chittagong, Bangladesh, talapatraakash@gmail.com
}

(Received 20 May 2019, Accepted 9 June 2019)

\begin{abstract}
Coalbed methane is extracted from the adsorbed state in coal seams with lower pressure and production rate. In previous studies, researchers only focused on the methods that were developed for making a relationship between the underground production rate and surface flow rate without any type of optimization procedure. In this study, the main purpose is to do a review on finding out of surface layout plan to optimize the maximum gas flow rate by developing an improved pipeline network. The more the optimization of the layout plan for designing pipeline network, the lower the amount of investment need to provide. Here, a mathematical model is proposed for the gas transportation based on the hydraulic and thermodynamic calculations of the pipeline network. Not only that, but also the filtration mechanism of depressurization and desorption for the gas flow through pipe section are evaluated here. After that, the pressure drop and pipeline efficiency are explored to find out the best design of pipeline network from the observed results. Finally, based on this study, many uncertainties can be reduced associated with the installation of pipeline network for gas transportation.
\end{abstract}

Keywords: coalbed methane, gas transportation, pipeline network, hydraulic calculation, layout optimization

\section{INTRODUCTION}

Coalbed methane (CBM) is considered as an unconventional type of gas that is differentiated from the other conventional gases by its extraction, well optimization methods etc. The term unconventional source is linked with the methane gas for the reason that the methane gas is generally adsorbed in solid matrix of the coal seams [1]. This adsorbed gas is not extracted with similar procedures that are used in extracting of conventional gases. That's why the pipeline network for transporting the extracted gas into the surface for distribution [2]. The surface and underground conditions can effect on the flow of gas through pipeline section. Not only that, the length and the diameter of the whole pipe section can change the gas flow through pipeline network. So, according to the variation of these parameters, the pressure difference between two pathways through the pipeline section can be continuously alternated [3-5]. Before starting the design of a pipeline network, a collection of studies should be researched to stand an appropriate model for the gas transportation through surface. In previous studies on this gas transportation system, there had been exercised basically on the geometric method without any types of optimization procedure $[6,7]$. There had not been done any studies on the layout and flow rate optimizations for the planning of network designs. Here, the pipeline network is designed based on a structural network of 'tree' connection, which is connected between two nodes considered as the network by determining the shortest possible pathway and finding the optimum layout plan. These connections can consider the single line or multiple lines installation on the whole gas transportation network. After that, the location of the surface, gas flow rate and topography of the distribution line are utilized to generate tree network for the pipe section. 
However, a flowchart of the gas transportation process has been drawn in Figure 1, for providing an overview of the total design of pipeline network. The parameters need for designing transportation system have to be optimized according to the requirements of this flowchart. Not only that, but also the specification of the location and geometry of the sites should be selected with using a technical surveying. If the pressure and flow distribution are changed at a certain time, then the system must has the ability of updating the pipeline network according to the above changes. When the total layout plan and design of the pipeline network can be completed successfully, then it would be convenient for the investor to invest on these set up of pipe line network for gas flow distribution without any type of doubts. Finally, the flow of coalbed methane will be distributed uniformly through the surface pipeline network to the main gas distribution system.

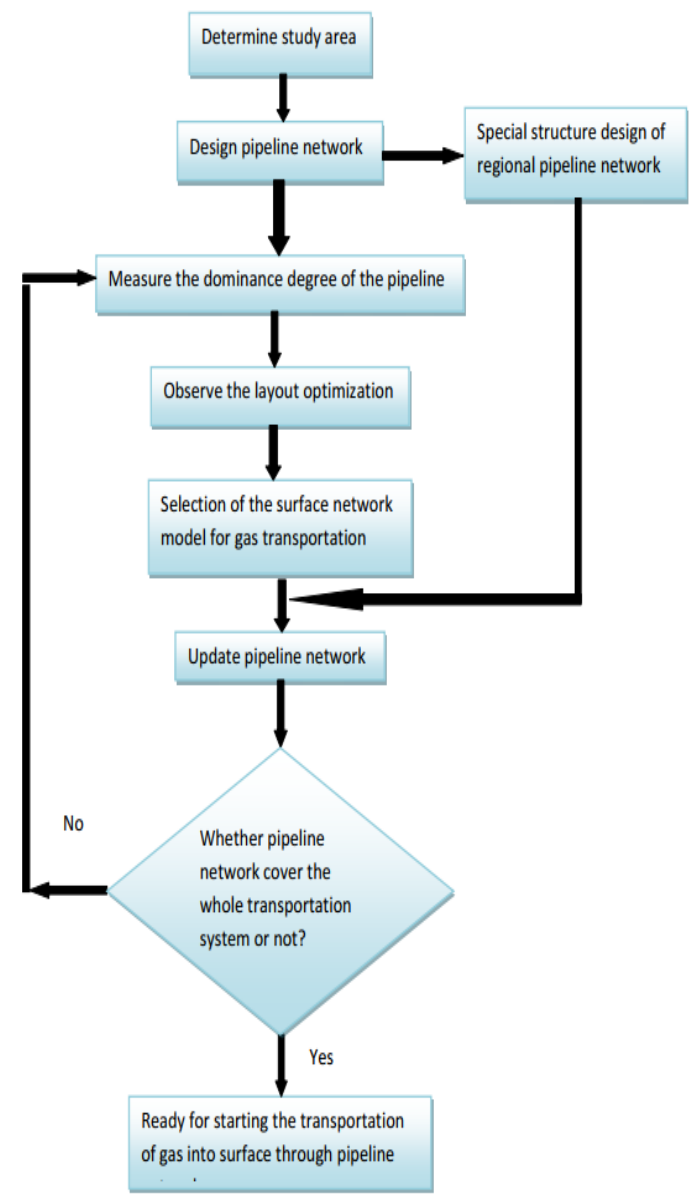

Fig. 1. Steps of gas transportation process

\section{MATHEMATICAL MODEL OF OPTIMIZATION}

To optimize the surface pipeline network of transportation system, the following observation should be made to perfectly find out the design:

- location of the geometric sites;

- flow distribution between the various diameters of pipelines;

- pressure variation through the entire pipeline;

- two phase gathering flow of oil and gas through their interfaces;

- selection and specification of materials and equipments in each section the pipeline network.

Since, the entire pipeline network contains variables of both in continuous and discrete connection, so it is almost impossible to provide a similar network system for the entire pipeline. This problem is known as 'Hybrid complex optimization problem' in engineering theory. So, to make some uncontested and appropriate assumptions for the pipeline network system, it is suggested to separate the whole optimization design into two parts. First one is considered as design of layout optimization and second one is considered as design of diameter optimization $[8,9]$.

\subsection{Design of layout optimization}

This type of optimization is made based on the surface structure, site location and interconnected relationships to form a shape of pipeline network. The design of this function can be defined as following:

$$
\max f=Q\left(t, X_{s}\right)-f\left(t, X_{s}\right),
$$

where, $F$ - objective of function; $T$ - discrete variable of pipeline network; $X_{s}$ - optimization variable of surface network; $Q\left(t, X_{s}\right)$ - income from the gas per cycle; $f\left(t, X_{s}\right)$ - investment in the pipeline network.

This study of optimization is tried to decline the amount of investment for gathering the site pipelines together to minimize the errors occurred during the evaluation of tree structure problems.

The mathematical expression of the function $f\left(t, X_{s}\right)$ is defined as follows:

$$
f=\sum_{i=1}^{n} \sum_{j=1}^{n} A_{i j} w_{i} d_{i j}
$$

The disciplinary formulations of that relationship are as follows:

$$
\begin{gathered}
1 \leq \sum_{i=1}^{n} A_{i j} \leq(n-1), \\
1 \leq \sum_{j=1}^{n} A_{i j} \leq(n-1), \\
\sum_{i=1}^{n} \sum_{j=1}^{n} A_{i j}=2(n-1), \\
A_{i j}=0,1,
\end{gathered}
$$

where, $i, j$ - point of nodes; $n$ - number of nodes; $w_{i}$ - volume of gas at node (i), $\mathrm{m}^{3} / \mathrm{d} ; d_{i j}$ - length of pipeline from node I to node $\mathrm{j}(\mathrm{km}) ; A_{i j}-$ section variable of decision $(0,1)$. 
When, two nodes I and $\mathrm{j}$ are jointed then it is taken as ' 1 ', but if the nodes are not jointed, then it is taken as ' 0 '. Equation (3) and (4) express the condition, where at least one node is connected with another node. Equation (5) and (6) are provided for indicating the section constraint and value constraint of the pipeline network, respectively.

\subsection{Diameter optimization}

The optimum diameter of each pipe section can be measured, when the layout design of the entire pipeline network is optimized. If it is completed properly, then the investment cost associated with the process of designing the pipeline diameter in each section is reduced. Once the optimized layout of pipeline network system is established, then the structure of the established network and direction of gas flow are also measured. Since, the direction of gas flow differs in every section of the pipeline, so it can be perceived that the required diameter of every section is also be varied along with the variation of its installation and maintenance costs. Not only that, but also it is not simple to select an exact diameter with required design in the tree network system of pipeline. The main purpose of this optimization study is to select a least pipeline section with required diameter so that it can meet all of the requirements of pipeline section.

The optimum diameter of pipe section is expressed as below:

$$
\min f=\sum_{i \in m}\left[C\left(D_{i}\right) \times L(i)\right],
$$

The further formulations of optimization diameter for pipeline section are provided as:

$$
\begin{gathered}
R(i) \times D_{i}^{\frac{-16}{3}} \leq P_{i}^{2}-P_{i+1}^{2}(i=1,2, \ldots, m), \\
P_{\min } \leq P_{i} \leq P_{\max }(i=1,2, \ldots ., m+1),
\end{gathered}
$$

where, $L_{i}$ - length of the pipe, i (m); $C\left(D_{i}\right)$ - cost for the installation of required diameters; $D_{i}-$ diameter of the pipe, i (cm); $R_{i}$ - coefficient of flow conversion; $P_{i}, P_{i+1}$ - Pressure at each node; $P_{\text {min }}-$ pressure at lowest node $(\mathrm{MPa}) ; P_{\max }-$ pressure at highest node (MPa).

Here, equation (8) indicates relationship between pressure drop and gas flow, where equation (9) shows the operating pressure of each pipeline section.

\section{EVALUATION OF CBM DVELOP- MENT TECHNOLOGIES BASED ON THE FILTRATION MECHANISM OF DEPRESSURIZATION AND DESORPTION}

Though, the coalbed methane is usually desorbed in water, but when the pressure will reduce, the coalbed methane will be injected in a gaseous state from the coal seams. Then, the ejected gas will be entered through matrix pores and cleats, in where, there is existed a plenty numbers of fractures with various sizes. Here, a non-linear filtration technology is considered for examining the flow of free gas through the matrix pores and cleats $[10,11]$. But, instead of using conventional theory concentration difference driving, here newly proposed pressure difference driving is applied. The development of pressure difference theory is dependent on the nonlinear filtration mechanism of two phase flow, reservoirs physical characteristics, distribution of gaswater conjugation etc. The influence of the pressure difference theory on the reservoir condition is not so negligible, rather it priors to consider for the development of CBM reservoir.

\section{RELATIONSHIP BETWEEN METHANE AND WATER IN VARIOUS MATRIX PORES}

Here, the occurrence of methane in the coal matrix is evaluated by observing the production of methane from the matrix pores. These matrix pores contain some capillary channels, where the channels are consisted of a few number of capillary tubes in parallel way. A simple model named 'Capillary bundle model' is applied to introduce the coal seam as an ideal type of rock. After that, the porosity resulted from the model is expressed as:

$$
\varphi_{m}=\frac{V_{p}}{V_{b}}=\frac{n\left(\pi r_{c}^{2}\right) L_{c}}{A_{m} L_{c}}=\frac{n \pi r_{c}^{2}}{A_{m}},
$$

The surface of specific rock is formulated as:

$$
S_{s}=\frac{a}{V_{b}}=\frac{n\left(2 \pi r_{c}\right) L_{c}}{A_{m} L_{c}}=\frac{n \pi r_{c}^{2} \times 2}{A_{m} r_{c}}=\varphi_{m} \frac{4}{d},
$$

where, $n$ - number of capillary tubes; $\varphi_{m}$ - porosity of the model; $V_{p}$ - pore volume $\left(\mathrm{m}^{3}\right) ; V_{b}$ - rock volume $\left(\mathrm{m}^{3}\right) ; r_{c}$ - radius of capillary tubes $(\mathrm{m}) ; L_{c}-$ length of capillary tube (m); $A_{m}-$ cross-sectional area of coal's matrix $\left(\mathrm{m}^{2}\right)$; a - surface area of the rock $\left(\mathrm{m}^{2}\right)$; $d$ - diameter of the capillary tube (m).

The ratio of the gas and water molecules number at the unit section of the matrix pore with unit volume can be expressed as follows:

$$
\frac{N_{w}}{N_{g}}=\frac{V_{S w} /\left(3 / 4 \times \pi R_{l}^{3}\right)}{a_{s g} / \pi R_{g}^{2}}=\frac{3 d S_{w m} R_{g}^{2}}{16 R_{l}^{3}},
$$

where, $N_{w}$ - number of water molecules; $\mathrm{Ng}$ - number of gaseous molecules; $V_{s w}$ - water volume in the porous media $\left(\mathrm{m}^{3}\right)=\varphi_{\mathrm{m}} \mathrm{S}_{\mathrm{wm}}\left(1-\varphi_{\mathrm{p}}\right) ; a_{s g}-$ gas surface area $\left(\mathrm{m}^{2}\right)=4 \varphi_{\mathrm{m}}\left(1-\varphi_{\mathrm{p}}\right) / \mathrm{d} ; R_{l}$ - radius of water molecule (m); $R_{g}$ - radius of methane molecule $(\mathrm{m})$.

After evaluating the diameters of water and methane molecules using different equations, the ratio of $N_{w} / N_{g}$ is determined for various micro pores. The distribution of gas and water molecules from the micro pores has greater impact on the methane transport arrangements based on the variation of molecules 
ratio. A general overview of the relationship between the number ratio of gas and water molecules and the diameters of micro pores is shown in Figure 2. From Figure 2, the observed result would be substituted in equation (12), to find the number of gaseous molecules, when diameter of micro pore and number of water molecules are known.

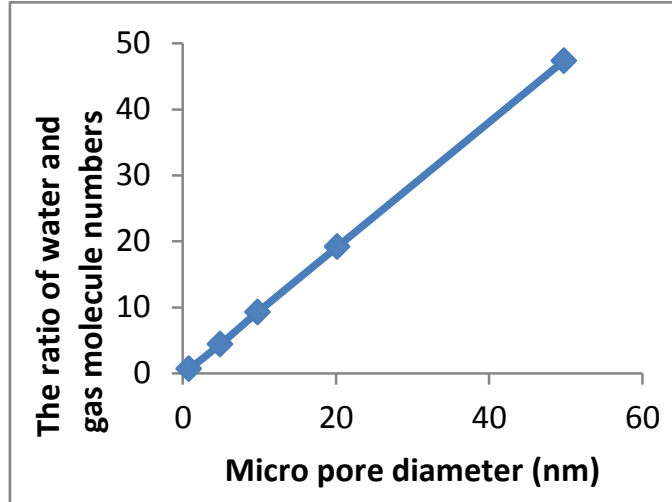

Fig. 2. The ratio of water and gas molecule numbers in different micro pore

\section{PRODUCTION OF GAS FROM SMALL MATRIX PORES}

Gas productions are varied according to the variation of matrix pore diameters. Here, for making the study of evaluation of gas production more simplifier, the diameter of pore less than $50 \mathrm{~nm}$, is considered as the small matrix pore. From the Figure (2), it can be said that when the diameter of pore is taken at $50 \mathrm{~nm}$, then the measured number of gas molecule is counted about $1 / 50$ of the number of water molecule. Within the small matrix pore, the methane gas must be congealed more to form gaseous bubbles $[12,13]$. Though, the small amount of expansion force is not adequate to be generated within the small pores, yet the bubbles are tried to force them for filtrating within the pores. Even then, in small matrix pores, it is very difficult for the gas molecules to mobilize. As a result, the stacked gaseous molecules are considered as the residual gas and have low energy to release from the small pores. That's why, recovery of methane gas from these small pores is very low to consider.

\section{SURFACE PIPELINE NETWORK MODEL}

\subsection{Hydraulic model of pipeline}

The pressure drop is the one of the main parameters to arrange all of the data required for designing a network of pipeline installation. The gas flow through the pipeline should be in steady-state condition. That's why the main theme of the hydraulic calculation would be designing to determine the pressure drop occurring through the pipeline. In below, a mathematical model is given to calculate the pressure drop as:

$$
q=\frac{\pi}{4} \sqrt{\frac{\left(P_{Q}^{2}-P_{Z}^{2}\right) D^{5}}{\lambda Z R T L}}
$$

where, $q$ - mass flow rate, $\mathrm{Kg} / \mathrm{s} ; P_{Q}$-inlet pressure of pipe, $\mathrm{MPa} ; P_{Z}-$ outlet pressure of pipe, $\mathrm{MPa} ; D-$ inlet diameter, $\mathrm{m} ; \lambda-$ hydraulic friction coefficient, dimensionless; $Z$ - gas compressibility factor, dimensionless; $R$ - universal gas content, $\mathrm{J} /(\mathrm{mol} \mathrm{K})$; $T$-temperature, $\mathrm{K} ; L$ - pipe length, $\mathrm{m}$.

\subsection{Hydraulic calculation of pipeline network}

Before starting the hydraulic calculation for pipeline system, the pipeline network should be divided into $\mathrm{n}$ nodes and $\mathrm{m}$ section from the wellhead to surface portion. Since, the pipeline section is divided into $\mathrm{n}$ nodes, so there is also having $\mathrm{n}$ number of continuity equations for gas flow. The form of the flow continuity equations for the node matrix equation is given in following form as:

$$
A Q=P,
$$

where, $A$ - correlating matrix of node and pipe; $Q$ - pipe flow vector; $P$ - node pressure vector.

Now, a vector form is used to show the relationship between the flow rate and pressure drop in each pipe section designed as:

$$
Q=\emptyset(\Delta P),
$$

where, $\varnothing-$ vector coefficient, dimensionless; $\Delta P$ - pressure drop, $\mathrm{MPa}$.

Again, a pressure difference equation is used to express the pressure drop in each pipe section by the following form:

$$
\Delta P=A^{T} P
$$

where, $\mathrm{A}^{\mathrm{T}}$ - transpose matrix of $\mathrm{A}$.

After substituting the equations (14), (15) and (16), the mathematical form for the node matrix is expressed as:

$$
A\left[\varnothing\left(A^{T} P\right)\right]=q,
$$

\subsection{Thermodynamic calculation of pipeline network}

After observing the steady-state hydraulic calculation, the thermodynamic analysis is initiated. Now, a temperature drop equation in gaseous phase is used to calculate the temperature drop in pipeline section by the following form:

$$
T=T_{0}+\left(T_{Q}-T_{0}\right) e^{-a x},
$$

where, $T_{0}$ - ambient temperature, $\mathrm{K} ; T_{Q}$ - temperature of the starting point of the pipeline, $\mathrm{K} ; e-$ absolute roughness, $\mathrm{m}$; $a x$ - coefficient, dimensionless. 


\section{FACTORS OF INFLUENCING THE PRESSURE DROP CURVE OF THE PIPELINE NETWORK}

Based on the gas compositions and the pipeline network condition (Tab. 1-2), it is found that temperature, pipe wall roughness, pipeline efficiency can affect the pressure drop through the pipeline section [14]. For analyzing the effect of temperature change on the pressure drop of the pipeline, the difference of temperature is taken from $10^{\circ} \mathrm{C}$ to $50^{\circ} \mathrm{C}$ (Fig. 3).

Tab. 1. Gas composition.

\begin{tabular}{lc}
\hline Composition & Volume Fraction (\%) \\
\hline $\mathrm{C}_{1}$ & 98.70 \\
\hline $\mathrm{C}_{2}$ & 0.40 \\
\hline $\mathrm{CO}_{2}$ & 0.20 \\
\hline $\mathrm{N}_{2}$ & 0.30 \\
\hline $\mathrm{H}_{2} \mathrm{O}$ (Saturated water) & 0.40 \\
\hline
\end{tabular}

Tab. 2. Conditions of transporting the gas flow through pipeline

\begin{tabular}{lc}
\hline Parameters & Value \\
\hline Pressure at starting point, $\mathrm{MPa}$ & 0.5 \\
\hline Capacity for transmission, $\mathrm{m}^{3} / \mathrm{d}$ & $1 \times 10^{4}$ \\
\hline Heat transfer coefficient, $\mathrm{W} / \mathrm{m}^{2} \cdot \mathrm{C}$ & 1.75 \\
\hline Pipe diameter, $\mathrm{mm}$ & 110 \\
\hline Roughness of wall, $\mu \mathrm{m}$ & 30 \\
\hline Pipe material & $\mathrm{PE}$ \\
\hline Temperature at starting point ${ }^{\circ} \mathrm{C}$ & 25 \\
\hline Length of pipeline $\mathrm{Km}$ & 10 \\
\hline Ambient temperature, ${ }^{\circ} \mathrm{C}$ & 5 \\
\hline Thickness of wall, $\mathrm{mm}$ & 10.0 \\
\hline Efficiency of pipeline & 0.95 \\
\hline
\end{tabular}

It can be observed that the effect of inlet temperature on the pressure drop is very negligible. Though, the outlet temperature of the pipe section is decreased with the enhancing of inlet temperature, still the range of change is negligible to consider. Here, from Figure (b), the value of pressure drop is found only $0.4 \mathrm{KPa}$, which is the maximum difference at the inlet temperature changes from $10^{\circ} \mathrm{C}$ to $50^{\circ} \mathrm{C}$. When the variation of temperature between the inlet section of the pipe and the ground is increased, the inlet temperature is also changed. After that, the increasing inlet temperature increases the heat transfer between the soil and pipe section, by which the outlet temperature change is very negligible in the pipe section.

Now, the roughness of pipe wall has little effect on the pipeline pressure drop. It is observed from Figure
(4) that the pressure drop through the pipeline section increases along with the increasing variation of the roughness on the pipe wall, whe'n the variation of inlet pressure drop is certain. But, when the pressure drop is low, then the roughness of the pipe wall can't affect the normal transportation of gas so much through the pipeline network.

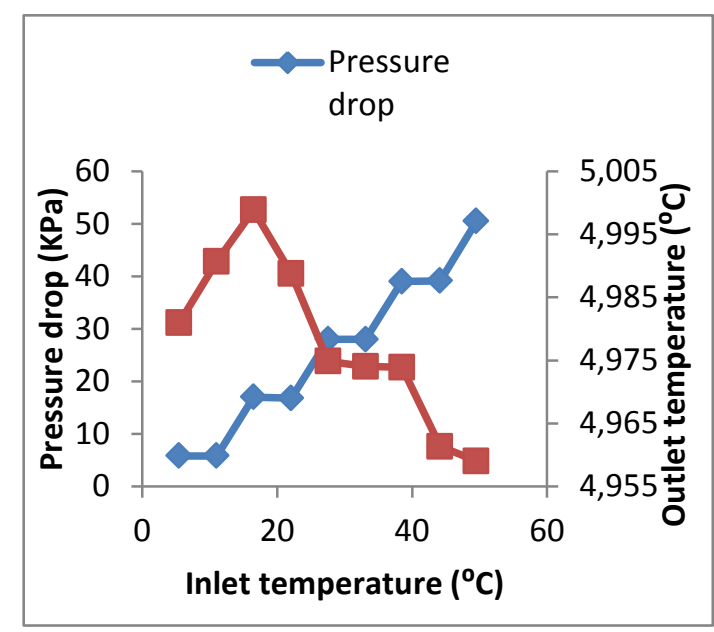

Fig. 3. Pressure drop curves based on the various inlet temperatures

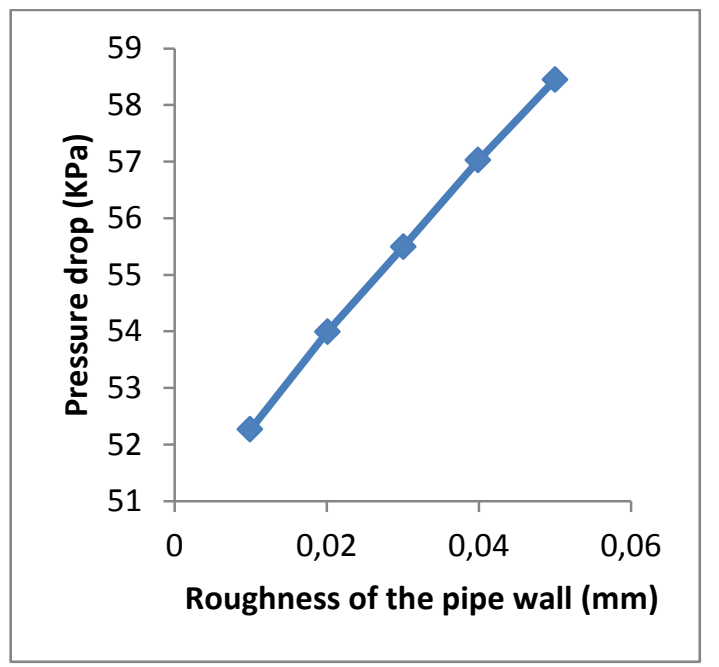

Fig. 4. Pressure drop curves based on the various roughness of the pipe wall

In Figure (5), the effect of pipeline efficiency on the pressure drop during the transportation of gas is investigated. When the pipeline efficiency is increased, then the outlet pressure and pressure drop of the pipeline section are continuously increased and decreased, respectively. It should be noted that due to the change of 5-5.5\% efficiency, the pressure drop is change about 20-25 KPa, which is considered as a linear change through the pipe section. 


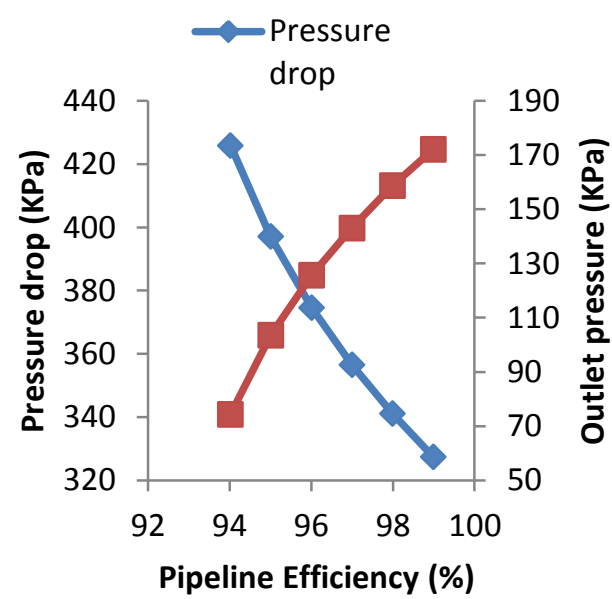

Fig. 5. Pressure drop curves based on the various pipeline efficiencies

\section{TECHNOLOGICAL CHALLENGES FOR A SAFE DESIGN OF COALBED METHANE GAS TRANSPORT PIPELINES}

The industries and authority must have higher level of experiences on transporting the methane gas through pipelines. The behavior and physical characteristics of the methane gas as an anthropogenic carbon fuels can affect on the transportation system [15]. Here are given some issues that should be kept in mind at the time of designing safe transportation process for the methane gas flow:

- since, methane gas is more susceptible than the conventional gases, so the pipeline transportation in long running transportations should be designed based on the working conditions,

- since, the decompression curve of methane gas is very acute, so it is also assumed that the driving force will also be very strong to create cracks in the pipeline. That's why an approximate mechanical crack arrester can be used to detect the crack in the pipeline,

- to reduce the ductile fracture propagation of a pipeline, a reinforced steel meshing should be higher toughness,

- Joule Thomson Cooling effect should be considered to evaluate the effect of low or higher operating temperature through the pipeline section that can reduce the pipeline toughness,

- also it should be checked continuously to reduce the amount of free water in the methane gas flow so that the free water flow can't create corrosion through the pipeline,

- a proper technology should be used with experiencing the transition of pipeline to detect the leakage of the pipeline so that the pressure of gas flow can't be reduced.
All of the above mentioned issues should be considered during the designing of a safe pipeline network.

\section{CONCLUSION}

Coalbed methane gas transportation into surface from coal seams is not similar with the normal transportation of other conventional gases. Some strategically developed plan should be designed to draw a structure of pipeline network for the whole methane gas transportation from coal mines. Since, the structure of the total pipeline network of the gas transportation is basically for the gas distribution over a region, that's why the design should be designed on dynamic situation of many rules and regulations related with the installation of pipeline network so that it can keep contribution in the uniform distribution of this unconventional gas. In this case, the optimization of the layout plan and degree of uncertain influential factors should be evaluated essentially for getting the best results. The parameters related with the optimization of surface pipeline network model should be integrated to an approximate optimization in order to increase the pipeline efficiency for the transportation of methane gas. There are many uncertainties existed with the installation of pipeline network. These uncertainties are considered not only the limitation, but also the hindrance to the designing a pipeline model for surface installation. The uncertainties are basically resulting from the length and diameter of each section of pipeline, pressure and temperature variation according to the inlet and outlet conditions of the pipeline. So, the future studies should be run on finding some reference systems practically or theoretically based on which, these limitations and uncertainties related with the designing of pipeline network model can be solved. By which, the transportation of unconventional methane gas from coal seams will be further easier to transport into the surface without any systematic or precautionary losses.

\section{Acknowledgement}

Great thanks are presented to a regional director of the of China coal mining plant for providing me some information to write this paper.

\section{References}

1. Li J., Yang J. (2011). Brief discussion on development of coal seam gas industry in China. SCI-TECH Innov Prod., $8,20-22$.

2. Zhou Shining, Lin Baiquan.(1992). The storage and flow of coalbedmethane. Beijing: China Coal Industry Publishing House, 122127.

3. Li X.F., Pu Y.C., Sun C.Y., Ren W.N., Li Y.Y., Zhang Y.Q., Li J., Zang J.L., Hu A.M., Wen S.M.(2014). Recognition of absorption/desorption theory in coalbed 
methane reservoir and shale gas reservoir. Acta Pet. Sin., 35, 1113-1129. (In Chinese)

4. Li J.H., Su X.B., Lin X.Y., Guo H.Y.(2009). Relationship between discharge rate and productivity of coalbed methane wells. J. China Coal Soc., 34, 376-380.

5. Liu S.Q., Sang S.X.. Li M.X, Liu H.H., Wang L.L. (2012). Control factors of coalbed methane well desorption cone under drainage well network in southern Qinshui basin. J. China Univ. Min. Technol., 41, 943-950.

6. Herran-Gonzalez A., De La Cruz J.M., De Andres-Toro B., Risco-Martin J.L.(2009). Modeling and simulation of a gas distribution pipeline network. Applied Mathematical Modelling,33, pp. 1584-1600.

7. Hwang K., Mandayan S., Udpa S.S., Udpa L., Lord W., Atzal M.(2000). Characterization of gas pipeline inspection signals using wavelet basis function neural networks. NDTandE international,33, pp. 531-545.

8. Zhang J., Zhu D.(1996).A bilevel programming method for pipe network optimization. J Optim., 6, 838-857.

9. El-Mahdy OFM, Ahmed MEH, Metwalli S.(2010). Computer aided optimization of natural gas pipe networks using genetic algorithm. Appl Soft Comput., $10,1141-1150$.

10. Singh R. R., Nain P. K. S.(2012). "Optimization of natural pipeline design and its total cost using GA," International Journal of Science and Research Publications, 2,8, pp. 1-10.

11. Alves F. D. S., Souza J. N. M. D., Costa A. L. H.(2016). "Multiobjective design optimization of natural gas transmission networks," Computers and Chemical Engineering, 93, pp. 212-220.

12. Trick M. D., Agarwal R., Ammer J. R. (1994). Gas-Field Deliverability Forecasting: A Coupled Reservoir Simulator and Surface Facilities Model, USDOE Morgantown Energy Technology Center.

13. Coats B. K., Fleming G. C., Watts J. W., Rame M., Shiralkar G. S. (2004). "A generalized wellbore and surface facility model, fully coupled to a reservoir simulator," SPE Reservoir Evaluation and Engineering, 7,2, pp. 132-142.

14. Lockhart RW, Martinelli RC. (1949). Proposed correlation of data for isothermal two-phase, twocomponent flow in pipes. Chem Eng Prog., 45, 39-48.

15. Gale J. (2002). Transmission of CO2: safety and economic considerations. Sixth Int. Conference. on Greenhouse Gas Control Technologies, Kyoto, September, 1-4.

\section{Biographical notes}

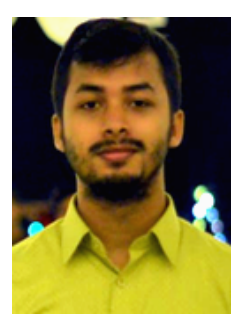

Akash Talapatra is currently studying Bachelor of Science in Engineering in Department of Petroleum and Mining Engineering from Chittagong University of Engineering and Technology (CUET), a reputed university of Bangladesh. He published two or more articles on environmental and energy engineering. His current research area focuses on the topic of alternative production and transportation of coalbed methane gas or its equivalent resources from the coalmine fields.

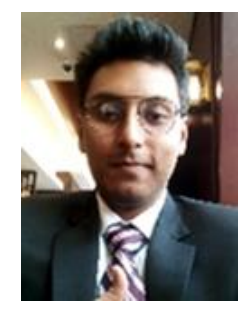

Abed Inan Chowdhury is pursuing Bachelors of Science degree in Petroleum and Mining Engineering Department at CUET. He is currently working on various research projects including but not limited to Petroleum Reservoir Engineering, Environmental Science and Enhanced Mining Systems.

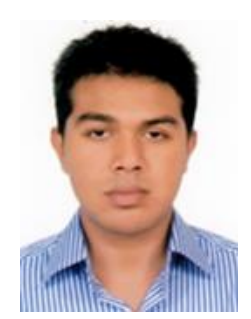

Md. Shourov Ujjaman is currently studying Bachelor of Science in Engineering in Department of Petroleum and Mining Engineering from CUET, a reputed university of Bangladesh. He is interest to work on environment and energy related things and now he is working on the carbondioxide (CO2) emission and how to sequestrate it by efficient ways. His current research area focuses on the topic of carbon-di-oxide emission from mine fields and gas fields and its consequence to the near zone areas calculating vegetation index by NDVI technique and temperature increases due to excessive emission of $\mathrm{CO} 2$ by LST technique. 
